\title{
The pedicle elongation of submental artery perforator flap for reconstruction in the head and neck
}

\author{
Sisi Lee ${ }^{1}$, Xuexin Tan ${ }^{1}$, and kunming Zhao ${ }^{1}$ \\ ${ }^{1}$ Department of Oromaxillofacial-Head and Neck Surgery, School of Stomatology, China \\ Medical University,Shenyang 110002, Liaoning, China.
}

August 21, 2021

\begin{abstract}
15 patients successfully received submental artery perforator flaps with its pedicle elongated. The lesions were located in tongue,oropharynx,gingiva,mandible,auricle,infraorbital skin,buccal mucosa and parotid gland.All patients are satisfied with the reconstruction. 15 patients' donor sites were recovered well and the flaps survival was $100 \%$ with no post-operation or further major complications occurred
\end{abstract}

\section{Introduction}

The optimal way to reconstruct defects is the characteristics of donor site matching the recipient site and restore the function with less expenditure.Martin ${ }^{[1]}$ and his team had convinced submental artery island flap(SMAIF) is appropriate for oral and facial defects by many surgeons in 1993 for the first time. He also stated the submental artery island flap is able to reach the whole most part of homolateral face except a part of the forehead for reconstructing maxillofacial moderate defects.Preferably,it meets the requirement of donor site invovle color,texture, proportion,thickness and so on.A large amount of free flaps,regional flaps and pedicle flaps can be used for reconstructing facial and oral defects according to the range of defects.Free flaps usually are not suitable for large defect with esthetic outcomes, besides, those are not suitable for elderly patients in poor general condition especially who cannot suffer from lengthy operations ${ }^{[4]}$. Howerver,the submental artery island flap perfectly matches facial skin color,texture and reduces costs as an axial pedicle flap ${ }^{[2]}$. Nevertheless, the authors were concerns about the risk of nodal metastases with bulk in it.The perforator flap conception introduced by Koshima and Soeda in 1989 for repairing floor-of-mouth and groin defects $^{[3]}$. For the distal defects site reconstruction, there are several optional approaches to elongate the pedicles of submental artery island flap ${ }^{[4]}$.In this study,we ingeniously elongate the pedicle of submental artery perforator flap range from $3.9 \mathrm{~cm}$ to $5.4 \mathrm{~cm}$ by reporting 15 cases to reconstruct distal defects beyond its regular reconstruction range in head and neck with no ligating main vessel in security. What's more,the techniques can expand the application scope and benefit more patients and surgeons.

\section{Materials and methods}

This is a retrospective study that from January 2019 and February 2021 at China Medical University,Oral \& Maxillofacial Head and Neck Tumor Center, 15 patients (9 men and 6 women)in the aggregate presented to our department successfully received submental artery perforator flap reconstruction after resecting their aggressive malignant tumor involving oral and facial area en bloc by Dr.Xuexin Tan.The all available medical information and parameter referring demographics,pathology diagnosis, defect site,flap size,postoperative complications,pedicle length difference, and flap survival rates were recorded in Table 1. The primary lesions were 11 cases of squamous cell carcinoma (SCC), 1 case of Merkel cell carcinoma (MCC), 1 case of osteosarcoma, 1 case of sebaceous gland carcinoma and 1 case of adenoid cystic carcinoma (ACC).All patients had 
underwent primary renconstrution with submental artery perforator flap after tumor resected integrally.

\section{Anatomy}

The perforators of submental artery perforator flap is the branch off from submental artery flap mainly passes through the platysma muscle from submental vessels ${ }^{[5]}$.It is reported that the in the $70 \%$ of patients and dissections,it goes deep to the anterior belly of the digastric muscle,nevertheless in $30 \%$,it runs superficial to it ${ }^{[5,6]}$. It is evidenced that only one perforators and its concomitant venous vessels is sufficient to support the blood of the flap ${ }^{[7]}$. The other perforators are glandular branch to the sublingual salivary gland and submandibular gland,and several perforators supply and run to the platysma muscle,mylohyoid muscle,overlying skin and the periosteum of the mandible ${ }^{[8,9]}$. The facial vein has no values and it usually are variable so that its concomitant plays an essential role in venous drainage.

\section{Surgical Technique}

Head-mounted loup magnification is equipped.The patients are in the supine position with head and neck extended under general anaesthesia. The upper border of the flap is designed under edge of the mandibular arch to avoid eversion of lip and visible facial scar ${ }^{[10]}$. The horizontal scope of the flap can extend to bilateral mandibular angle,and the width of the flap is assessed by the pinch test according to the proportion of the defects and the intrinsic extension of skin allowing the donor site can be closed primarily.The gonion is marked by gentian violet in order to preserve the marginal mandibular nerve.Under normal conditions, the external jugular veins are not included. The original length of the vascular pedicle was measured from the beginning of the submental artery from the facial artery to the skin point near the proximal flap. According to the distance from the defect area, the length of the vascular pedicle after the submental artery perforator entering into the mandible hyoid muscle, the length of the vascular pedicle after the submental perforator artery entering into the submandibular gland, and the length of the vascular pedicle after ligating the mylohyoid nerve were dissected and measured.(fig1 and 2) During the operation, the traction was reduced ,which the three step by step approachs are not mentioned to date. The mylophoid muscle were appositional sutured in order to preserve tissues and increase safety as much as possible ${ }^{[11]}$.

The maximal flap is $6.5 \times 16 \mathrm{~cm}$ (representing $104 \mathrm{~cm}^{2}$ ) is transferred successfully to the distal recipient site without any flap loss,facial nerve temporary or permanent palsy.It is safe that flap can be harvested synchronously with no including lymphoid tissue, fat and bulky digastric muscle by neck dissection for nodal metastasis concerns.

\section{Case report:}

Case 1:A 42-year-old male patient was diagnosed with SCC(squamous cell carcinoma)of the left auricle. The submental artery perforator flap size is $4.5 \times 9 \mathrm{~cm}$. During the operation, the vascular pedicle was lengthened by $0.9 \mathrm{~cm}$ after ligating the submental artery perforator into the mandibular hyoid muscle, $2.1 \mathrm{~cm}$ after ligating the submental artery perforator into the submandibular gland, and $2.1 \mathrm{~cm}$ after ligating the mylohyoid nerve. The length of pedicle in total is elongated $5.1 \mathrm{~cm}$ which can easily reach the upper facial area.The flap is $100 \%$ survived.(fig3)

Case 2:A 66-year-old female patient was diagnosed with Merckel cell carcinoma on her left cheek.She was reconstructed with a $3.5 \times 6 \mathrm{~cm}$ submental artery perforator flap after tumor resection. During the operation, the vascular pedicle was elongated $0.8 \mathrm{~cm}$ by ligating the submental artery perforator into the mandibular hyoid muscle, $2.0 \mathrm{~cm}$ after ligating the submental artery perforator into the submandibular gland, and 1.7 $\mathrm{cm}$ after ligating the mylohyoid nerve. The patient is satisfied with the flap. (fig4)

\section{Results}

Between January 2019 to February 2021,15 patients were performed the submental artery perforator flap to reconstruct oral and maxillofacial defects in head and neck in our department. The population consist of 9 men and 6 women ranged from 29 to 72 years in age(mean age of (55+-13)years old). The size of flaps range from $3.5 \mathrm{~cm} \times 6 \mathrm{~cm}$ to $6.5 \mathrm{~cm} \times 16 \mathrm{~cm}$. The mean elongation length of pedicle is $(0.9+-0.2 \mathrm{~cm})$ by ligating the perforators 
branches to mylohyoid muscle, $(2.0+-0.2 \mathrm{~cm})$ by ligating the perforators branches to submandibular gland, $(1.8$ +- $0.2 \mathrm{~cm})$ by ligating the perforators branches to mylohyoid nerve. The mean elongated length is $(4.7+-$ $0.4 \mathrm{~cm}$ ). Due to the elongation of the pedicle,the submental artery perforator flap can be rotated to distal site above midface for construction of the primary tumor sites including aural defects in 1 patients, infraorbital skin in 1 case, parotid gland in 1 case, tongue in 5 cases, oropharynx in 2 cases,gingiva in 1 case,mandible in 1 case, buccal mucosa in 3 cases. All patients' donor defects were closed primarily and recovered well.The continuous follow-up vary from 2 to 20 months with no major complications or temporary or permanent marginal mandibular facial nerve palsy and none of them were diagnosed nodal metastases negatively.The flap survival rate is $100 \%$ in all patients without venous congestion problems. The patients were satisfied with its functional and cosmetic effect espcially the well-hidden scar below the edge of mandibular arch and less economical costs.

\section{Discussion}

Lots of various of flaps can be used for resurfacing of the defects in head and neck following cancer ablation $^{[7,12,13]}$. The total mean operative costs and the time of hospitalization compared to the free flaps ${ }^{[2]}$.

In recent years, with the extensive application of microvascular microsurgical technique in the reconstruction of larger defects, the success rate of free flap transplantation has improved. But now, submental artery island flap or its perforator flap has gradually shown its advantages which are more suitable and ideal for reconstruction with multiple characteristics. It is commonly used in the repair of small and mediumsized defects of oral and maxillofacial tissues. It is an ideal donor site flap. In the donor site repaired by submental artery perforator flap, the scar is more hidden, and the neck skin is tighter and smoother after repair, even most patients achieve additional neck rhytidectomy effect ${ }^{[4,14]}$.In particular, most of the patients with malignant tumors are middle-aged and elderly patients. The skin tissue of the neck is relatively loose, which increases the distance in the width direction for the flap design, and the scar hyperplasia of the donor site is not obvious after postoperative healing. The thickness and volume of the flap are moderate ${ }^{[15]}$. The primary wound repaired with the flap is smooth, with small tension and good aesthetic effect. Basically, there is no dog ear deformity ${ }^{[13]}$ similar to that formed in the operation area of the adjacent flap. Therefore, it is not necessary to carry out the secondary repair of the facial deformity. Usually, the tissue in the defect area can not be directly sutured because of the close distance to the facial features or the large defect of the facial features. Otherwise, the facial tissues or other organs will be easily displaced and deformed, which will affect the appearance and lead to physical and mental disorders. The submental artery perforator flap can basically solve this problem. However, it is worth noting that when the donor site wound is closed, it is not allowed to sneak too much to separate the skin on the surface of the jaw, so as to avoid obvious symptoms of lower lip valgus [20], which does not affect the facial appearance. All patients with maxillofacial repair were sutured with thin 3-0 silk thread. The healing effect of tissue and flap was good, and scar hyperplasia was less.

In this study, the rotation radius of submental artery perforator flap was extended by extending the vascular pedicle. The length from the beginning of submental artery to the distal end of the flap can reach $15 \mathrm{~cm}$ or more. Therefore, the submental artery perforator flap can easily repair not only the lower face, but also the middle and upper part of the face according to Chinese Physiognomic facial height. It can completely repair small and medium-sized defects and deformities, and its performance is better than or even can replace the forearm flap. It makes up for the lack of tissue in the adjacent flap and avoids the bulkiness of the distant pedicled flap (such as pectoralis major myocutaneous flap) ${ }^{[16]}$

There are four methods to elongate the submental artery perforator flap ${ }^{[1,4,16-18]}$ : 1 .Additional dissection of the pedicle;2. Y-V procedure;3. Reverse flow;4. Hybrid flap with vein microvascular anastomosis.Up to now, there hasn't no reports about repairing the defect with the vascular pedicle of the submental artery perforator flap. In the previous literature, the method of lengthening is selective and risky. Among them, the fourth method can extend the vascular pedicle by $5 \mathrm{~cm}$ to repair the farther soft tissue defect ${ }^{[16,19]}$, but microvascular anastomosis needs the support of microsurgical technology, and it is also easy to cause the common problems of free flap, such as venous reflux obstruction, congestion or transplantation failure ${ }^{[14,18]}$. 
But these methods not only increase the operation time and flap observation time, but also increase the postoperative complications of flap. This study is totally different from the traditional submental artery island flap extension method, using microsurgical techniques to dissect and ligate the relationship between submental artery perforator and surrounding tissue to achieve the effect of extension, that is, cut off the submental artery perforator into the mylohyoid muscle, submental artery perforator into the submandibular gland, mylohyoid nerve. Due to the spiral bending characteristics of blood vessels, after leaving the binding of fascia, muscle and other tissues, there will be physiological rebound and the length will become longer. According to the research data, the longest rotation radius of submental artery perforator flap is about $5.4 \mathrm{~cm}$, which further expands the scope of the flap repair indications. It can easily reach the lower part of zygoma and orbit, the parotid gland area and even the temporal bone in the middle and upper maxillofacial region. In general, if the first or the first two methods are enough to repair the defect, the subsequent methods can be retained. In clinical practice, if the length of the designed flap slightly exceeds the mandibular angle by $1-1.5 \mathrm{~cm}$, the survival of the flap will not be affected, and the rotation radius of the vascular pedicle will also be increased. In all operations, the surgeon used a 2.5 times head mounted magnifying glass to "skeletonize" the vascular bundle to find the location of the perforator, and carefully separated and dissected it. Because of the application of microsurgical technique in operation, it is possible to measure vascular pedicle precisely. Therefore, the skilled anatomical knowledge and microsurgical techniques of the operator are the key factors for the success of vascular anatomy and the basis for smooth blood flow. Improper anatomical operation can easily lead to flap crisis ${ }^{[20]}$. It should be noted that in the process of measurement and transfer of perforator vascular pedicle, we must take a gentle, tension-free and torsion free operation, otherwise it is easy to lead to the failure of flap transplantation. In this study, both antegrade blood flow mode and no vascular anastomosis mode were used to dissect and separate the vascular pedicle, so the blood supply of submental artery perforator flap was better protected. The perforator flap with more abundant and stable blood supply and the feature of rich blood supply in maxillofacial region make the healing effect of the flap combined with maxillofacial defect area more effective. After the operation, a drainage strip was placed immediately in the mouth or the edge of the maxillofacial skin flap, and the drainage strip was removed 24-48 hours according to the situation of the drainage, which can make the skin flap adhere well and effectively reduce the complications such as subcutaneous hematocele, edema and cavity. All flaps survived completely. The incidence rate of donor site of the flap is lower. ${ }^{[21][22]}$ If reconstruct the same defect area, microsurgical techniques for anastomosing anastomoses are needed. At least two doctors should have four hands to cooperate with each other, which increases the scope and difficulty of operation. Postoperative arterial anastomosis is more safe than vein. It is easy to cause vascular stenosis due to anastomotic stenosis, and postoperative care is also more complicated. Compared with the free flap, the flap does not need to open new wounds from other parts, which reduces the operation time, operation cost, postoperative hospital stay and operation and nursing staff ${ }^{[23,24]}$. Generally speaking, the family economic status of patients with malignant tumor is more difficult. Economically, the average cost of repair in the same range can save more than $40 \%$ compared with free flap ${ }^{[22,23]}$. The choice of this operation can greatly alleviate the family economic burden and pressure.

During the continuous follow-up of 15 patients, there are still limitations in this study. 1 . The problem of hair growth on the flap is common in submental artery island flap and submental artery perforator flap. In terms of classification, the hair problem of male patients is more serious than that of female patients, and that of European is more serious than that of Asian. If further from the perspective of plastic surgery to solve the problem, usually can be used laser hair removal method, focus area radiotherapy or secondary operation skin flap epithelization to solve the problem of hair growth. As an important part of the body, the head, neck and maxillofacial region cannot be completely removed by conventional mechanical methods, and laser hair removal is often the preferred method ${ }^{[25]}$. For patients with malignant tumor, with postoperative radiotherapy, the hair in the flap will gradually stop growing; 2 . If there is a large defect or deformity in the oral cavity, maxillofacial or accompanied by bone tissue, the repair effect is often not as good as the free flap; 3. The preparation process of submental artery perforator flap requires high microsurgical technology, and special training and learning are needed in clinical application. 4.Although it can successfully repair the defect, the sample population of this study is limited. As a kind of research that can be widely used 
in clinical research in the future, a large number of sample population data are still needed to support this technology.

\section{Conclusion:}

The technical of prolong pedicle of submental artery perforator flap provides superior alternative choices for surgeons to extend of the mean arc of rotation of 3.9-5.4cm and take advantage of its predominant advantages as fine texure match,color and well-concealed donor scars with aesthetic outcomes, to construct oral and maxillofacial defects caused by tumore resection, trauma,traffic-accident injuries, burn injuries,severe infections,malformation,maldevelopment and so on.

References:

1. Martin, D., et al., The submental island flap: a new donor site. Anatomy and clinical applications as a free or pedicled flap.Plast Reconstr Surg, 1993. 92 (5): p. 867-73.

2. < Cost effectiveness of microsurgical reconstruction for head and neck defects after oncologic resection.pdf>.

3. Koshima, I. and S. Soeda, Inferior epigastric artery skin flaps without rectus abdominis muscle. Br $\mathrm{J}$ Plast Surg, 1989. 42 (6): p. 645-8.

4. Ferrari, S., et al., The submental island flap: pedicle elongation and indications in head and neck reconstruction. J Craniomaxillofac Surg, 2014. 42 (6): p. 1005-9.

5. Ishihara, T., et al., Submental perforator flap: location and number of submental perforating vessels. Scand J Plast Reconstr Surg Hand Surg, 2008. 42 (3): p. 127-31.

6. Chen, W.L., et al., Facial contour reconstruction after benign tumor ablation using reverse facial-submental artery deepithelialized submental island flaps. J Craniofac Surg, 2010. 21 (1): p. 83-6.

7. Huang, L., et al., Reconstruction of intraoral defects after resection of cancer with two types of submental artery perforator flaps. Br J Oral Maxillofac Surg, 2018. 56 (1): p. 34-38.

8. Martin, D., et al., [The submental island skin flap. A surgical protocol. Prospects of use]. Ann Chir Plast Esthet, 1990.35 (6): p. 480-4.

9. Faltaous, A.A. and R.J. Yetman, The submental artery flap: an anatomic study. Plast Reconstr Surg, 1996. 97 (1): p. 56-60; discussion 61-2.

10. Karacal, N., et al., Reverse-flow submental artery flap for periorbital soft tissue and socket reconstruction. Head Neck, 2006.28 (1): p. 40-5.

11. Sittitrai, P., et al., Submental island flap reconstruction in oral cavity cancer patients with level I lymph node metastasis. Br J Oral Maxillofac Surg, 2017. 55 (3): p. 251-255.

12. Rigby, M.H. and R.E. Hayden, Regional flaps: a move to simpler reconstructive options in the head and neck. Curr Opin Otolaryngol Head Neck Surg, 2014. 22 (5): p. 401-6.

13. Pletcher, S.D. and D.W. Kim, Current concepts in cheek reconstruction. Facial Plast Surg Clin North Am, 2005. 13 (2): p. 267-81, vi.

14. Abouchadi, A., et al., The Submental Flap in Facial Reconstruction: Advantages and Limitations. Journal of Oral and Maxillofacial Surgery, 2007. 65 (5): p. 863-869.

15. Kim, J.T., et al., An anatomic study and clinical applications of the reversed submental perforator-based island flap. Plast Reconstr Surg, 2002. 109 (7): p. 2204-10.

16. Amin, A.A., et al., The submental flap for oral cavity reconstruction: extended indications and technical refinements. Head Neck Oncol, 2011. 3 : p. 51. 
17. Chen, W.-L., et al., Two Submental Island Flaps for Reconstructing Oral and Maxillofacial Defects Following Cancer Ablation. Journal of Oral and Maxillofacial Surgery, 2008.66 (6): p. 1145-1156.

18. Hayden, R.E., T.H. Nagel, and C.B. Donald, Hybrid submental flaps for reconstruction in the head and neck: part pedicled, part free. Laryngoscope, 2014. 124 (3): p. 637-41.

19. < TwentyFive Years of Experience with theSubmental Flap in Facial ReconstructionEvolution and Technical Refinements following311 Cases in Europe and Africa.pdf>.

20. Bin, X., et al., Surgical anatomy of the submental artery perforator flap and assessment for application in postoperative reconstruction following oral cancer surgery: a prospective clinical study. Int J Oral Maxillofac Surg, 2020.

21. Cariati, P., et al., Is submental flap safe for the oncological reconstruction of the oral cavity? J Stomatol Oral Maxillofac Surg, 2018. 119 (4): p. 284-287.

22. Miller, C., et al., The submental island flap for reconstruction of temporal bone defects. Otol Neurotol, 2015.36 (5): p. 879-85.

23. Forner, D., et al., Submental island flap reconstruction reduces cost in oral cancer reconstruction compared to radial forearm free flap reconstruction: a case series and cost analysis. J Otolaryngol Head Neck Surg, 2016. 45 : p. 11.

24. Maharaj, K., et al., Re: Assessment of surgical outcomes and oncologic safety for submental artery perforator flap reconstruction after ablation of oral cancer. Br J Oral Maxillofac Surg, 2020.

25. Rahpeyma, A. and S. Khajehahmadi, A Protocol for Management of the Hairs Problem in Oral Cavity Reconstruction by Submental Flap. J Maxillofac Oral Surg, 2017. 16 (1): p. 108-112.

\section{Hosted file}

fig1.docx available at https://authorea.com/users/431208/articles/534732-the-pedicleelongation-of-submental-artery-perforator-flap-for-reconstruction-in-the-head-and-neck

\section{Hosted file}

fig2.docx available at https://authorea.com/users/431208/articles/534732-the-pedicleelongation-of-submental-artery-perforator-flap-for-reconstruction-in-the-head-and-neck

\section{Hosted file}

Fig3.docx available at https://authorea.com/users/431208/articles/534732-the-pedicleelongation-of-submental-artery-perforator-flap-for-reconstruction-in-the-head-and-neck

\section{Hosted file}

fig4.docx available at https://authorea.com/users/431208/articles/534732-the-pedicleelongation-of-submental-artery-perforator-flap-for-reconstruction-in-the-head-and-neck 